\title{
Power speed characteristics of a novel double-stator PM generator integrated with a magnetic gear
}

\begin{abstract}
This paper describes the power speed characteristics of a novel double-stator permanent magnet generator integrated with a magnetic gear (MG) using 2-D finite element method (2D-FEM). The machine is proposed for low-speed applications and it has a novel structure with two iron ring pole pieces and three permanent magnet rotors consisting of an outer field PM, inner field PM and prime PM. A prototype of the proposed machine is constructed and tested experimentally. The power characteristics including voltage, current, torque and speed are analyzed and compared with the measured results. The measured power characteristics are in good agreement with the calculated results but there is limitation on the measured speed characteristics which is primarily due to the constraint on the transmission torque of the magnetic gear. The predicted and measured results validate the proposed machine design.
\end{abstract}

Keyword: Power; Magnetic gear; Double-stator; Generator; Permanent magnet; Torque; 2DFEM 